\title{
HERALD (Health Economics using Routine Anonymised Linked Data)
}

\author{
Muhammad J Husain ${ }^{1 *}$, Sinead Brophy', Steven Macey ${ }^{1}$, Leila M Pinder ${ }^{1}$, Mark D Atkinson ${ }^{1}$, Roxanne Cooksey ${ }^{1}$, \\ Ceri J Phillips ${ }^{2}$, Stefan Siebert ${ }^{1}$ \\ From Clinical Trials Methodology Conference 2011 \\ Bristol, UK. 4-5 October 2011
}

\section{Background}

Health economic analysis traditionally relies on patient derived questionnaire data, routine datasets, and outcomes data from experimental randomised control trials and other clinical studies, which are generally used as stand-alone datasets. Herein, we outline the potential implications of linking these datasets to give one single joined up data-resource for health economic analysis.

\section{Method}

The Health Information Research Unit (HIRU) at Swansea University has set up the Secure Anonymised Information Linkage (SAIL) databank, which brings together and links a wide range of anonymous patient-level data $[1,2]$. The linkage of individual level data from questionnaires with routinely-captured health care data allows the entire patient journey to be mapped both retrospectively and prospectively. We illustrate this with examples from a population-based Ankylosing Spondylitis (PAS) cohort [3] by linking patient reported study dataset with the routinely collected general practitioner (GP) data, inpatient (IP) and outpatient (OP) datasets, and Accident and Emergency department data in Wales.

\section{Potential benefits of data linkage}

The linked data system allows: (1) retrospective and prospective tracking of patient pathways through multiple healthcare facilities; (2) validation and clarification of patient-reported recall data, complementing the questionnaire/routine data information; (3) obtaining objective measure of the costs of chronic conditions for a longer time horizon, and during the pre-diagnosis period; (4) assessment of health service usage, referral

${ }^{1}$ College of Medicine, Swansea University, Swansea, SA2 8PP, Wales, UK Full list of author information is available at the end of the article histories, prescribed drugs and co-morbidities; and (5) profiling and stratification of patients relating to disease manifestation, lifestyles, co-morbidities, and associated costs.

\section{Results}

Using the GP data system we tracked 183 AS patients retrospectively and prospectively from the date of questionnaire completion to gather the following information: (a) number of GP events; (b) presence of a GP 'drug' read codes; and (c) the presence of GP 'diagnostic' read codes. We tracked 236 and 296 AS patients through the OP and IP data systems respectively to count the number of OP visits; and IP admissions and duration. The results are presented under several patient stratification schemes based on disease severity, functions, age, sex, and the onset of disease symptoms.

\section{Conclusion}

The linked data system offers unique opportunities for enhanced longitudinal health economic analysis not possible through the use of traditional isolated datasets. Additionally, this data linkage provides important information to improve diagnostic and referral pathways, and thus helps maximise clinical efficiency and efficiency in the use of resources.

\section{Acknowledgements \\ Funding for the PAS cohort was provided by a Medical Research Council (MRC) and National Institute for Social Care and Health Research (NISCHR) grant (G080058).}

\section{Author details}

${ }^{1}$ College of Medicine, Swansea University, Swansea, SA2 8PP, Wales, UK. ${ }^{2}$ College of Human and Health Sciences, Swansea University, Swansea, SA2 8PP, Wales, UK.

Published: 13 December 2011 


\section{References}

1. Lyons RA, Jones KH, John G, Brooks CJ, Verplancke JP, Ford DV, Brown G, Leake K: The SAIL databank: linking multiple health and social care datasets. BMC Medical Informatics and Decision Making 2009, 9:3.

2. Ford DV, Jones KH, Verplancke JP, Lyons RA, John G, Brooks CJ, Thompson S, Bodger O, Couch T, Leake K: The SAIL databank: building a national architecture for e-health research and evaluation. BMC Health Services Research 2009, 9:157.

3. Atkinson MD, Brophy S, Siebert S, Gravenor MB, Phillips C, Ford DV, Jones KH, Lyons RA: Protocol for a population-based Ankylosing Spondylitis (PAS) cohort in Wales. BMC Musculoskeletal Disorders 2010, 11:197.

doi:10.1186/1745-6215-12-S1-A44

Cite this article as: Husain et al:: HERALD (Health Economics using Routine Anonymised Linked Data). Trials 2011 12(Suppl 1):A44.

\section{Submit your next manuscript to BioMed Central} and take full advantage of:

- Convenient online submission

- Thorough peer review

- No space constraints or color figure charges

- Immediate publication on acceptance

- Inclusion in PubMed, CAS, Scopus and Google Scholar

- Research which is freely available for redistribution

Submit your manuscript at www.biomedcentral.com/submit
Ciomed Central 